\title{
La promoción del turismo musical: los festivales de música en Facebook
}

\section{Luisa Chierichetti ${ }^{\mathrm{i}}$}

Università degli Studi di Bergamo (Italia)

\begin{abstract}
Resumen: Este artículo pretende aportar una contribución al estudio del uso de redes sociales como recurso para la comunicación y la promoción turística, centrándose en el caso específico de los festivales musicales en Facebook (FB). A través del análisis cualitativo de un corpus de estudio constituido por una selección de páginas FB de festivales españoles, se destacan la hibridez y la polifonía como principales características de esta producción discursiva. Asimismo se subraya cómo el uso de redes sociales en un ámbito turístico rellena un hueco en la comunicación promocional, ya que no solo facilita la interacción con la comunidad de referencia y la obtención de datos sobre la satisfacción del cliente, sino que ejerce una influencia positiva en las intenciones de comportamiento.
\end{abstract}

Palabras clave: Turismo cultural; Turismo musical; Festival de música; Facebook; Redes sociales

Title: Promoting Music Tourism: Music Festivals on Facebook

\begin{abstract}
This paper aims to contribute to the study of social networks as a resource in tourism communication and promotion, through the case of music festivals on Facebook (FB). Following a qualitative approach, the discourses of a selection of FB pages about Spanish festivals were analysed, emphasizing hybridity and polyphony as main features. Results also suggest that the use of social network in tourism facilitates the interaction between attendees and their respective community and provides data on customer satisfaction, while exerting a positive influence on patronizing intention.
\end{abstract}

Keywords: Cultural Tourism; Music Tourism; Music Festival; Facebook; Social Networks 


\section{Introducción}

El verano pasado, en el mes de julio, El País recogía un reportaje titulado Turismo de playa y festival, cuyo subtítulo rezaba "La música se convierte en un nuevo pilar de la oferta veraniega española - Muchas ciudades la usan para competir con destinos más baratos del Mediterráneo". En el artículo, el alcalde de Benidorm, donde por segunda vez se había celebrado el Festival Low Cost, declaraba:

Yo he hecho esto pensando en el turismo más que en la cultura. Es fundamental que tengamos muchísima variedad. Otros países como Turquía y Grecia tienen el obstáculo de no contar con una capacidad como la nuestra. Solo en Benidorm hay 45.000 plazas de hotel. Intentar montar un festival como este en otra ciudad que no tenga infraestructura, es muy complicado. En eso estamos por delante. No podemos competir en los precios con otros países emergentes. Pero yo creo que España tiene capacidad para muchos festivales. Hay público (López Palacios, 2011).

La música es tal vez el más singular y efímero tipo de patrimonio cultural que motiva desplazamientos turísticos. Actualmente el turismo musical mueve a personas que se alejan cada vez más del estereotipo de principios del siglo XX del "turista de elevado nivel social y cultural, sensible al patrimonio que contempla y altamente predispuesto a dejar una elevada cantidad de dinero en los lugares que visita" (Calle Vaquero, 2002: 87). Al insertarse en una concepción de la cultura mucho más amplia y compleja, se constituye en una de las manifestaciones del consumo cultural de masas característico de las sociedades industriales avanzadas. Está generalmente caracterizado por su estacionalidad (short break), y puede segmentarse en función del tipo de contenidos musicales que, con cierta aproximación, determina grupos de usuarios distintos y suficientemente homogéneos. Dejando a un lado los festivales de música culta (serious music), que atraen preferentemente a una audiencia con un poder adquisitivo medio-alto y que se sitúan en el segmento post-family nos centramos en los espectáculos que incluyen a autores, intérpretes y DJS de musica pop, rock, electrónica y se dirigen a un público mayoritariamente pre-family ${ }^{1}$, prefieren una receptividad y unos medios de transporte de bajo coste (acampadas, hostales; car sharing) y se celebran en lugares no tradicionalmente designados.

En España, la localidad levantina de Benidorm, como también Benicàssim con el Festival Internacional de Benicàssim (FIB) y más recientemente el Rototom Sunplash, son villas litorales con tradición de turismo musical; hay más localidades costeras que potencian su industria turística con los festivales, como son Isla Cristina (Huelva) con el South pop, el Puerto de Santa María con el Monkey Week, Murcia con el SOS Murcia y el Electromar, Castellón con el Arenal Sound, Barcelona con el Primavera Sound, Bilbao con el BBk Live, Gijón con el Love Joy Club, el Santander Music Festival, Vigo Transforma y otros más. La situación geográfica abarca destinos con una relativamente escasa tradición turística, como Alburquerque (Badajoz) con el festival Contempopránea, Villarrobledo (Albacete) con Viñarock, Aranda de Duero (Burgos) con Sonorama, Arriondas (Asturias) con Aquasella. Se trata de festivales que a menudo salen de las ciudades históricas y de los auditorios para instalarse en ciudades deportivas y al lado de playas. Dentro de una oferta muy variada y difícil de clasificar, cabe destacar una tendencia común a la especialización de géneros musicales que, junto con la estrecha relación económica con la industria discográfica - el espectáculo en vivo es un gran escaparate publicitario - permite que este tipo de festivales no esté afectado por el problema del déficit estructural con el que se enfrentan otros eventos musicales (sobre todo de música culta) 'burocratizados' y subvencionados (Frey, 2003; Benhamou, 2004) llegando a constituir un evento no solo cultural, sino de gran relevancia turística, con un significativo beneficio económico para el territorio.

Con este trabajo nos proponemos aportar una contribución al estudio del uso de redes sociales como recurso para la comunicación y la promoción turística, centrándonos en el caso específico de los festivales musicales en Facebook (FB). Este sitio web de redes sociales se sitúa en el entorno de la Web 2.0, que se caracteriza por ser un lugar público de encuentro de usuarios prosumers (acrónimo de producers y consumers) (Garibaldi, 2011: 19), un ágora virtual en la que las personas se encuentran y comparten los contenidos de una inmensa librería multimedial. Vamos a considerar, a través del análisis cualitativo de un corpus de estudio, la producción discursiva que se da en las páginas de esta red social, primero enmarcándola en las pautas de análisis para los géneros del turismo elaboradas por Calvi (2010, 2011) para luego identificar sus principales características en relación con los aspectos sociales e interactivos de los participantes. Partimos de la hipótesis de que el discurso de los festivales de música en FB se construye y desarrolla de manera textualmente híbrida, configurándose como un ejemplo significativo de promoción turistica que incluye también las voces potencialmente conflictivas e irreverentes de las personas quienes, interactuando en FB, desarrollan una actividad on line socialmente significativa que deja huellas textuales (Herring, 2004), escritas y multimedia, grabadas permanentemente, también con gran distancia espacio-temporal.

\section{El macrogénero Página FB de Festivales de Música}

Al tomar en consideración la producción de discurso en la promoción del turismo musical en FB y su relación con el contexto sociocultural, nos planteamos situar este evento comunicativo dentro de una estrategia de posicionamiento y de fidelización de clientes en un entorno turístico cada vez más extenso y competitivo. Estas prácticas sociales y discursivas mediadas por ordenador pueden agruparse en dos de los bloques principales propuestos por Calvi (2010: 
18-19): el de la gestión, al comprender las interacciones entre operadores y público, y el de la descripción y promoción del destino turístico. Las páginas FB de festivales de música se configuran como un macrogénero al ser productos que encierran una variedad de materiales muy amplia y por ser hibridaciones de secuencias textuales y de géneros informativos y persuasivos (básicamente guía práctica, anuncios publicitarios, folletos y páginas web) cuyo resultado final tiene un valor autónomo (Calvi, 2010, 2011). Este macrogénero funciona como un molde al que se adaptan, integrándose, los contenidos turísticos, bien en cuanto al patrón organizacional - extensión de los textos y de los aparatos multimediales e icónicos - bien en cuanto al enfoque funcional - mayor o menor relevancia de las funciones persuasiva, informativa, interactiva (Calvi, 2011: 16).

Entendemos por sitios web de redes sociales unos servicios basados en la web que permiten que los usuarios 1) construyan un perfil público o semi público en un sistema limitado; 2) articulen una lista de otros usuarios con quienes les une una conexión (amigos en Facebook) y 3) vean y enlacen su propia lista de conexiones con las de otros usuarios dentro del sistema. (boyd / Ellison, 2007).

Fundado en febrero de 2004, FB es uno de los más famosos sitios web de redes sociales; originariamente destinado a los estudiantes de la Universidad de Harvard, actualmente está abierto a cualquiera que tenga una cuenta de correo electrónico. Ha recibido mucha atención en la blogósfera y en los medios de comunicación al convertirse en una plataforma sobre la que terceros pueden desarrollar aplicaciones y hacer negocio a partir de la red social. Efectivamente, la red que se autodefine como "a social utility that connects people, to keep up with friends, upload photos, share links and videos" (http://www.facebook.com/ facebook?sk=info) lanzó en noviembre de 2007 el programa Facebook Ads, para las empresas que quieren aprovechar las oportunidades ofrecidas por el contacto potencial con cientos de millones de internautas, creando una presencia distinta del perfil tradicional de usuario. Bajo los rótulos Lugar o negocio local, Empresa, organización o institución, Marca o producto, Artista, grupo de música o personaje público, Entretenimiento, Causa o comunidad las páginas permiten crear y mantenerse en contacto con los aficionados, contando con servicios personalizados basados en los sectores de mercado. Además, FB ofrece la posibilidad de crear Social Ads, anuncios destinados a un grupo de usuarios con varias segmentaciones por contactos, edad, sexo y distribución geográfica.

$\mathrm{Al}$ seleccionar "Crear una página - Conecta con tus fans en Facebook" encontramos los rótulos arriba citados; para "Causa o comunidad" la plantilla de FB permite teclear un texto, mientras que en los demás casos hay que elegir entre las categorías de un menú desplegable la etiqueta adecuada para definir la empresa en cuestión. Si entendemos por 'festival' una celebración que se centra en un determinado tema, abierta al publico durante un período de tiempo limitado, que puede convocarse anualmente o con menor frecuencia, y que incluye eventos ais- lados (Grappi / Montanari, 2011: 1129) y la restringimos al ámbito de la música, nos encontramos con un fenómeno comercial difícil de encajar en las categorías propuestas por FB; muchos festivales eligen como etiqueta "Lugar o negocio local”, "Artista, grupo de música o personaje público", "Empresa, organización o institución" o también "Causa o comunidad".

Los contenido turísticos de las páginas FB van a integrarse, pues, en un género que no es propio del sector, amoldándose, no solo genéricamente al canal de difusión (Calvi, 2010), sino a una plantilla estándar bastante rígida y definida, en la que las páginas comerciales están equiparadas con los perfiles personales (las referencias en el sitio son alternativamente páginas y perfiles) y los potenciales o actuales clientes siguen siendo amigos, por mucho que compartan una comunidad virtual planeada y construida por especialistas del sector. El inconveniente de la rigidez del medio, que se sitúa en las antípodas de la creatividad del sitio web, se compensa con un amplio beneficio desde el punto de vista del márketing en general y aún más en una perspectiva turística, al permitir la interacción con la comunidad de referencia y, al mismo tiempo, proporcionar (por lo menos potencialmente) atención a los individuos. La interfaz de la archiconocida plantilla blanca y azul de FB despoja el mensaje comercial de su típica agresividad y "baja las defensas" del consumidor, pues inserta cognitivamente la operación comercial en un frame caracterizado como un ambiente en el que los individuos construyen su indentidad - con su discurso, aportando materiales icónicos y multimediales- a la vez que en un colectivo unido por un vínculo de solidaridad y aprecio. Encontramos esta estrategia de afiliación basada en la cortesía positiva en el texto de 2007 en el que FB presentaba la operación publicitaria como una gran oportunidad para mantenerse en contacto con los amigos y al mismo tiempo desarrollar y compartir aficiones de una manera cada vez más adaptada a los gustos o necesidades personales:

You now have a way to connect with things you are passionate about. We've launched Facebook Pages, which are distinct, customized profiles designed for businesses, bands, celebrities and more to represent themselves on Facebook.

We noticed people wanted to connect with their favorite music, restaurants, and brands; but there was no good place for these types of affiliations to exist. Now, there is a place for them and you can become a fan of whatever pages you choose in order to interact with your passions in new ways. You can post reviews for a local restaurant, buy tickets to a new movie, or be the first to get a heads up about new promotions. (http:// blog.facebook.com/blog.php?post=6972252130)

El grupo FB de un Festival se sitúa en un entorno proyectado para optimizar la interacción de tipo comunitario y es gestionado con la finalidad de lograr la rentabilización del uso de la red social. La figura profesional que se 
identifica con el Festival es el emisor de los mensajes o entradas (posts) del muro de FB que propone temas de discusión, crea eventos y mantiene el contacto con los usuarios; estos, por su parte, pueden escribir sus propios posts (las páginas son accesibles a todo el público, mientras que para interactuar hay que identificarse como usuario de una cuenta FB), declarar su aprecio (con el botón "Me gusta"), compartir la entrada con otros amigos o comentarla. Los amigos del Festival también tienen otros lugares de interacción como, por ejemplo, el Foro, las Notas, o la sección de Twitter. Se trata de una comunidad virtual de personas que no necesariamente se conocen off line, pero que posiblemente se encuentren o se hayan encontrado físicamente en el evento, aunque sin llegar a conocerse personalmente, que están unidas por el interés cultural hacia cierto tipo de música y por el interés turístico de querer asistir o asistir al festival. Este distanciamiento espacio-temporal en el que se intersecan intimidad e impersonalidad hace de FB un sistema abstracto absolutamente "moderno" (Giddens, 1994).

\section{Materiales, enfoque metodológico y organización del trabajo}

Los materiales analizados son los textos de los muros FB de cuatro festivales de música mayoritariamente destinados a un público joven: Aquasella Festival (música electrónica), Contempopránea (música pop), FIB (música electrónica) y Sonorama (música pop rock). El corpus, en formato electrónico, abarca alrededor de 245.000 palabras $\mathrm{y}$ se ha constituido reuniendo todo el material publicado en los muros de los festivales hasta agosto de 2011, con distintas consistencias según los casos (Sonorama a partir del 30/6/2009, FIB del 14/7/2011, Contempopránea del 11/3/2010, Aquasella del 1/6/2011). Decidimos incluir todo el material para disponer de un contexto lo más extenso y rico posible, en el que se pudieran considerar las típicas actividades desarrolladas en FB con sus pautas recurrentes, aunque, como ya comentamos, también hay otras áreas de discusión y de producción de discurso en FB relativamente menos utilizadas.

Nos planteamos considerar el discurso como uno de los elementos de las prácticas sociales que influyen en la sociedad y caracterizan a la modernidad tardía que al mismo tiempo vertebran y construyen; dentro de esta perspectiva, nos centramos en los cambios culturales creados por los avances en las tecnologías de la información, fijándonos en las nuevas posibilidades de relaciones interpersonales que se dan en FB entendido como esfera pública, constituida por una manera especial de usar el lenguaje en público (Chouliaraki / Fairclough, 1999). FB es una práctica sumamente compleja en su forma, en las relaciones sociales de su producción y en la red de prácticas en la que se inserta; se desarrolla a través de grandes distancias espaciales y temporales y depende de sofisticadas tecnologías de mediación (Chouliaraki / Fairclough, 1999: 41-42). Dentro de esta práctica, el uso comercial de sitios web de redes sociales es un cambio económico, social y cul- tural que existe como discurso y, al mismo tiempo, como una serie de procesos que se realizan fuera del discurso; a su vez, estos procesos están sustancialmente determinados por los discursos (Chouliaraki / Fairclough, 1999: 4).

Por lo que concierne a la organización del trabajo, el punto de partida es la identificación de los núcleos temáticos principales presentes en los muros de FB, basada en el análisis cualitativo del corpus, con la mirada puesta en los componentes que caracterizan una comunidad virtual ${ }^{2}$ y en la hibridación, vista como un recurso para la gestión de la autopresentación y de las relaciones interpersonales que maximiza la funcionalidad y la eficacia del discurso (Androutsopoulos, 2006: 426).

\section{Análisis}

En el discurso del emisor que representa el Festival se destacan las tres principales funciones de los géneros turísticos señaladas por Calvi (2011: 35): informar, instruir y persuadir. Dentro del marco de la promoción y de la persuasión se distinguen los posts ${ }^{3}$ caracterizados por el uso de formas apreciativas, afectivas e hiperbólicas (Calvi, 2006: 84) y la descripción positiva de la experiencia del Festival, que no se limita al hecho espectacular, como en (3), sino que alcanza el entorno paisajístico (1), (2), (4):

(1) AQUASELLA FEST Nunca nos cansaremos de decirlo, Aquasella esta rodeado de un paisaje unico. Ademas de disfrutar de actuaciones musicales de primer nivel, en Aquasella 2011 vas a gozar de un entorno natural increible. En cuanto pises el recinto y eches un vistazo te daras cuenta de que estamos hablando.Y como en un fin de semana tan largo es clave el descanso, os invitamos a que visiteis el bosque encantado de Aquasella.[...] 19 de julio a las 21.12

(2) AQUASELLA FEST Si estas cansado de ir fiestas a sudorosos clubs o espacios frios y sin vida no dudes en acercarte el primer fin de semana de agosto a nuestro festival. Aire puro, djs top a nivel mundial y sobre todo un ambiente increible que convertira tu estancia en Aquasella en una experiencia inolvidable. Nosotros lo tenemos claro, y tu??

13 de junio a las 18.05

(3) AQUASELLA FEST Aquasella 2011 supondra el debut de DJ Hell en el festival. Sobran las palabras para describir la contribucion de Hell a la musica electronica durante la ultima decada. Estamos seguros de que Helmut va a demostrar en nuestro festival porque es uno de los selectores mas destacados del globo. No te pierdas su actuacion si quieres ver como se maneja uno de los mas grandes en directo. 23 de junio a las 16.23

(4) AQUASELLA FEST Aquasella 2011, fin de semana en el valle de la musica. Llega el verano y nos apetece hacer planes para disfrutar.Si te encuentras en pleno proceso de diseno de tus vacaciones nuestra sugerencia es que te vengas con nosotros a Aquasella 2011. Nuestra propuesta es bien sencilla, musica electroni- 
ca de altisima calidad en un entorno natural incomparable en todo el pais.

13 de junio a las 18.05

El uso de adjetivos calificativos y de superlativos ya ampliamente descrito en los estudios sobre la lengua del turismo (Calvi, 2006) también sirve como anclaje de los materiales multimedia (sobre todo videoclips, pero también fotos) insertados en el texto con enlaces web que amplían intertextualmente de forma potencialmente infinita los límites de la red social:

(5) Contempopránea Oficial Qué ganitas de Xoel! Nuestro gallego del indie más universal vuelve este verano de Argentina para subirse al escenario de Contempopránea Cruzcampo y presentarnos las canciones del que será su nuevo disco en solitario. XOEL LOPEZ - Probando "joven poeta", un tema nuevo, en San Francisco (EEUU) www.youtube.com [...]24 de mayo a las 17.58

(6) Contempopránea Oficial ¿Contempopranea fue el Mejor Festival Musical en España en 2010? Vota y podrás ganar un viaje a un destino Vueling http://t. co/3yUxqUe

En los posts más propiamente centrados en la música y los artistas, el tono eufórico del emisor parece recrear el tempo acelerado y el volumen enérgico propio de DJS y locutores y se utiliza una serie de recursos lingüísticos propia de los sociolectos juveniles, de forma parecida a lo que se puede apreciar en la publicidad destinada a este tipo de usuarios (Hernández Toribio / Vigara Tauste, 2007), ya que los profesionales deben adaptar su competencia, sus conocimientos y mensajes a las necesidades y expectativas de un público que tiene diferentes intereses y formación (Linell, 1998: 151):

(7) Sonorama Aranda Y ahora nuestro concurso de Cortometrajes. Durante los días 3, 7 y 8 a las 20:30 en el Auditorio de Caja de Burgos tendrán lugar los visionados para elegir el premio del publico. NO FALTÉIS, HAY NIVELAZO14 de octubre a las 10:50

(8) AQUASELLA FEST Ahora que estamos calentando motores, que os parece ir repasando artistas que vamos a poder escuchar el fin de semana. Abrimos con video brutal, mas aun va a ser su actuacion en Aquasella.. Estamo solo a 48 horas de esto

La implicación abierta del destinatario se produce con el uso del deíctico de la segunda persona de singular y también de plural, con cierta alternancia también en el mismo post:

(9) AQUASELLA FEST Quieres saber quien va a clausurar esta edición el escenario principal de Aquasella 2011?? Estad atentos esta semana a esta pagina, hagan sus apuestas.

(10) AQUASELLA FEST Llego el dia, estan preparad@s para la cita musical del verano???, nos vemos en Aquasella 2011, una edicion en la que cumplimos nuestro quince aniversario y queremos que estes alli con nosotros. Esto es lo que vamos a vivir durante el fin de semana

Este recurso retórico, dominante en la promoción ge- neralmente publicitaria y también en la turística, al estar colocado en FB, permite la implicación real del interlocutor virtual (Dann / Liebman Parrinello, 2007: 12) que, efectivamente, tiene derecho de réplica. Durante el largo período de tiempo entre un evento y otro - aproximadamente un año - el Festival mantiene el contacto con el público recordando con videoclips e imágenes los conciertos pasados, fomenta las expectativas hacia el futuro y anima a la interacción entre los miembros de la comunidad virtual.

El uso de una red social sirve también para satisfacer las preguntas, a veces muy prácticas y concretas, del turista, pero la petición y el suministro de la información se producen también entre amigos. En algunos casos, el Festival no proporciona textos elaborados específicamente para FB, sino que se propone como receptor pasivo de la información y aglutina información extraída de distintas fuentes que, mayoritariamente, se encuentran en la web. La finalidad del Festival en FB es también la de facilitar el acceso de la comunidad a las informaciones, compartiendo el conocimiento de los textos de referencia; la voz ajena se revela con la indicación de la fuente citativa (11) o la inserción de conectores intertextuales de evidencialidad (Reyes, 1994: 17) como las comillas (12), pero también por el distinto formato de los enlaces, como se puede apreciar en los ejemplos anteriores (5), (6); a veces este recurso polifónico puede crear algún malentendido, como en (13):

(11) FIB http://www.facebook.com/fibfestival

Hotel Termas Marinas El Palasiet****

Hotel ubicado en los jardines de una antigua villa cla sica de principios del s. XIX. El Palasiet fue totalmente reformado en el 2002 y posteriormente ampliado en 2005. Esta situado en un enclave privilegiado a 50 m. frente el mar Mediterraneo y rodeado por el Desierto de las Palmas, bajo un clima suave y calido. Se caracteriza por ser uno de los hoteles mas sugestivos de la costa levantina debido a una decoracion muy personal y acogedora que le brinda encanto y originalidad. [...]

Mujer Del Hampa Demasiado estirado...El Voramar tiene mejores vistas y es mas cinematografico. El Bonaire, si te atienden bien, es otra opcion interesante.

07 de abril a las 10.53

Kikiycarol Marti Yo he estado mirando y no hay ningun tipo de alijamiento decente por menos de $100 €$ la noche, si alguien me puede recomendar algun sitio, lo agradeceria..

07 de abril a las 10.57

Cris Tinita Si quieres hotel / hostal... (vamos, una cama en vez de camping) creo que lo mas barato es mirar en Castellon, tal vez el Grao... Aunque los desplazamientos con transporte publico hasta Benicassim son un poco mierd. [...]

07 de abril a las 11.05

(12) Nuria Nurita Nurieta Y no habran autobuses la zadera desde arriondas?? 25 de junio a las 20.31 
AQUASELLA FEST"El festival se encuentra a escasos 200 metros de Arriondas, por lo que no es factible usar autobuses lanzadera debido a la cercania y al elevado volumen de trafico tanto a pie como en vehiculos que se produce ese fin de semana."

27 de junio a las 19.49

(13) Javier Fernandez Diaz este ano no pongais duchas, es demasiado caro, poner palanganas y una manguera

04 de julio a las 13.36

Jordi Pina problemas presupuestarios???? entonces por que narices los anunciais? espero no me recorteis a AF, Strokes, ARctic, Primal y traigais a vuestra prima tocando la vuvuzela!

04 de julio a las 13.49

FIB Javier, Jordi, es el grupo quien se ha encontrado con los problemas presupuestarios, no nosotros. El texto entrecomillado es el que nos ha pasado el propio grupo. Perdonad la confusion.

04 de julio a las 14.16

En otros casos el Festival no se limita a proporcionar información, sino que es más interactivo: contesta a algunos de los posts, reordena, reestructura y recoloca el discurso (13), (14), (15). En esta actividad se aleja de su función persuasiva e informativa, a veces actuando como moderador y entrando en un intercambio comunicativo concreto que puede producir el switch de la primera persona de plural corporativo, a la primera persona de singular (15) que "delata" al autor que está detrás de la identidad virtual del Festival (Yus, 2001: 64-67):

(14) Pablo Álvarez Ferreira Bueno, el abuso de las 125 libras es porque después los precios del FIB son a precio de guiri, porque una botellita de agua `pequeña 2,5 euros......... eso debería estar prohibido, ad+ en lisboa el festival Super Bock Super Rock ha tenido los mismos cabeza de carteles (arctic, strokes, portshead, arcada fire y kooks) y costaba 80 euros... si lo llego a saber antes va al Fib su madre jaja. Por lo menos me lo he pasado de puta madre. Un saludo.

27 de julio a las 14:14

FIB por favor, evitad hablar (bien, mal o regular) de otros eventos en la página oficial del FIB, gracias ;) 27 de julio a las 14:28

Pablo Álvarez Ferreira Ok, perdonad, que no sabia que las opiniones estan mal vistas, venga... ah! Guillermo, yo no sabia que costaba eso una botella de agua en un festival, pero vamos que en el Viñarock costaba 1 euro la pequeña... no son todos es éste...

27 de julio a las 14:34

FIB Pablo, para opinar libremente sobre el FIB (que es para lo que está pensada esta página) no hace falta que hagas referencia a otros eventos. Gracias por tu comprensión

de julio a las 14:38

(15) Elitxu Garcia por que borrais los comentarios de la gente? Si tienes presencia en redes sociales es para conversar y dejar que los usuarios hablen y si no, quedaros con la web y punto. Quereis nuestra opinion?
Pues aceptar las buenas y las malas, que todos somos libres de opinar

25 de marzo a las 16.50

FIB Elitxu, no se borran los comentarios porque contengan malas opiniones, pero no permitimos ni los insultos ni la publicidad de otros eventos. gracias por participar!

25 de marzo a las 16.52

Elitxu Garcia Me alegro que hagais escucha activa y que contesteis tan rapido, enhorabueana y gracias. Pero habeis borrado comentarios sin insultos y sin publicidad y me equivoco si digo que habeis vetado la posibilidad de seguir comentando a los usuarios censurados? No creo que eso sea muy etico, incluso antes de borrar o echar a alguien, se le debe informar de los motivos. 25 de marzo a las 17.02

FIB Elitxu, no hemos borrado comentarios sin insultos o sin publicidad (aunque me he podido equivocar, que soy humano!) tampoco hemos censurado usuarios (?) hace poco he bloqueado a un usuario que ha repetido el mismo mensaje en 10 sitios distintos (creo sinceramente que por el bien de todos, no? no era un mensaje negativo, era su listado de grupos) si quieres mandame un privado porque parece que estas hablando de un caso en particular, y te aseguro que no tengo ni idea de a que te puedes estar refiriendo.

25 de marzo a las 17.21

Elitxu Garcia Hola Fib! Creo que ya os habeis puesto en contacto por mail...me gustaria que se solucionase el tema, todos queremos un gran fib 2011 con el mejor cartel y la mejor organizacion. Gracias y nos vemos en el fib!

27 de marzo a las 16.12

En (14), (15) encontramos como apelativos los apodos o nombre de pila, como es habitual en los intercambios del muro para especificar al destinatario de la respuesta; los amigos también se dirigen al Festival con su "nombre", al que a veces se le añade el apelativo de cortesía, con cierta preponderancia en situaciones conflictivas o irónicas (16) (17) (18), (19):

(16) Jorge Martinez Diaz muxas gracias senor/a del fib nos vemos en benicassim : ) jajajaj 07 de julio a las 23.25

(17) Cabeza Casco Yo no entiendo como la gente pregunta tanto por los horarios, mira que son delicados, si con saberlo el mismo dia del festival sobra .verdad senor FIB?

08 de julio a las 18.39

(18) Carmen Abolafia una cosita Sr Fib, .vais a tener en cuenta nuestras sugerencias? ummmmmm 25 de noviembre 2010 a las 12.35

(19) Pablo Lz Sr Sonorama, qué tal?. Rectifico. Parte de los artistas y una web, se hacen eco de la confirmación de la orquesta poligonera. Ahora nos entendemos, esto sí es exclusividad. Confirmad algo, anda. Me consta que hay bandas que no aguantan más y comentan en "petit comité" su participación en el festival. Un último esfuerzo para Los Planetas y seguro que los 
reyes magos os traen muchas cosas por hacer feliz a tanta gente. Bien Sr. Sonorama, bien.

14 de junio a las 12:28

El intercambio en los muros se desarrolla casi exclusivamente en español, pero caben también posts en otras lenguas propias (22) y en inglés, como en (20) y $(21)^{4}$;.

(20) Laura Ibanez Martin no se puede escuchar a Brandon Flowers??

15 de julio a las 21.57

FIB Brandon Flowers no ha dado permiso para retransmitirlo (ni para hacer fotos)

15 de julio a las 22.07

Lee Shepherd No brandon flowers?

15 de julio a las 22.10

FIB Lee, no permission, sorry

15 de julio a las 22.28

(21) Simon 'Ronnie Cola' Partrick Watch for pickpockets in the crowd guys!!

15 de julio a las 10.11

Fernando Villar good festival for all people!...you have to learn spanish and write in spanish...jeje... buen fin de semana a todos en benicassim!

15 de julio a las 12.10

(22) Andrei Quintia Vena porfavor! Xa esta confirmando todo o mundo e vos ainda non soltades prenda! Ainda habedes perder asistentes por non confirmar a tempo... Moi ben o das curtas pero joder!!!!! Polo menos dicide cando ides confirmar..

09 de mayo a las 17.23

German Darder Rossello el portugues o brasileno tiene toda la razon del mundo.

09 de mayo a las 23.56

Jorge Martin Es gallego.

10 de mayo a las 2.20

La comunidad del Festival comparte un interés cultural por la música, y también un interés turístico "offline", el de participar en este tipo de eventos musicales y, de manera especial, en un Festival en concreto. Esta pertenencia al grupo está marcada por la construcción de una identidad comunitaria - fibers, fiberos, sonoritos, en los ejemplos del (23) al (31) - otorgada y reconocida por la organización festivalera (30).

(23) Coro Gonzalez Por intentarlo no perdemos nada: necesitamos recuperar el recuerdo de este pedazo FIB 2011 en fotografias. Perdimos una camara Sony Cibershot durante el concierto de Arcade Fire. Imagino que no hace falta deciros mas a los que sabeis que supone sentirse fiber...somos conscientes de que buscamos una aguja en un pajar, pero si suena la campana incluso nos conformamos con la tarjeta. Gracias y nos vemos dentro de un ano si no hay noticias antes ;) 21 de julio a las 19.21

(24) Gonzalo Blanco Querida organizacion, antes que fibers somos seres humanos!!! es inconcebible ver a gente durmiendo entre basura y que la zona de acampada sea un desierto de tierra y piedra donde no se puede clavar ni una piqueta y aun por encima haya vendavales que arrasan con todo. y con el clima arido de Benicassim la acampada deberia ser con sombra en todas partes, y si no la hay pues pongan mas toldos que para eso nos dejamos un ojo de la cara en el abono y sobre todo en el propio festival. el objetivo era SOBREVIVIR

19 de julio a las 11.50

(25) Claro de Luna una preguntilla, para los fiberos experimentados, se pueden meter bocadillos y tal? no hablo de bebida, pero en plan comida se puede? 29 de junio a las 10.40

(26) Alberto Gaya madre mia, Dorian y Julieta Venegas juntos el mismo dia!! Fibers, correis peligro.... 07 de abril a las 20.52

(27) David Font Por favor los FIBERS que vamos ano tras ano yendo al FIB, os pedimos que necesitamos otro ano como el 2008, donde los reyes fueron Justice, con su We are your friends, la gente se volvio loca, pero no mas que con su It's a disco. [...] 20 de noviembre de 2010 a las 13.03

(28) Pablo Navarro Vicent er es el autentico ANTIFIB!! jajajajajajajajaja!!...Ademas de ser el mayor conocedor de grupos que conozco y por supuesto el mejor cazatalentos que existe!! Por que no estas en la organizacion?!! WHAT THE FUCK!! ......

15 de junio a las 19.28

(29) Asun Sanz Rodriguez la gente de Aranda tb vamos al Sonorama y pagamos bonos y entradas. El domingo no suele haber Sonorama y este año es un extra ya q Amaral ha elegido el Sonorama para presentar su nuevo disco.Pero no es a 20 euros para q la gente de Aranda vayamos..okk? Ah! bienvenid@s Sonorit@s... hace calor,mucho calor..

11 de agosto a las 14:28

(30) Sonorama Aranda ¡Esos sonoritos! ¿Estáis ya en aranda? pues esta noche en el bar RASTATOO, gran JAM SESSION. Los instrumentos están a vuestra disposición para tocaros un temita. Nos vemos a las diez y media. Un momento especial...

10 de agosto a las 14:27

(31) Asier Garaikoetxea AYUUUUUUDA! necesito algun tipo de pack en el que se incluya trasporte desde navarra/pais vasco para ir al FIB solamente el sabado y volver!!!!!! POR FAVOR FAMILIA AYUDADMEEEE

11 de julio a las 15.50

Además de interactuar con el Festival, la comunidad de FB usa el discurso para hacer muchas cosas: opinar, comentar, criticar, discrepar, expresar afiliación y acuerdo, buscar y proporcionar información práctica sobre el Festival o sobre música, en una relación dialógica entre pares que está caracterizada, incluso en la crítica y la discrepancia, por el apasionamiento, cierto énfasis y la ironía, (32), (33); criticar sirve no solo para crear conflictos, sino que retroalimenta consenso y grupo (34):

(32) Arancha Rodriguez Perez cada uno va como le sale de los cojones yo nodigo ni qe pongan una cosa ni otra si no qe ya qe hay 3 zonas de musica qe pongan para todos los gustos y ya esta....a unos les gusta el 
schranz pues pa una carpa a otros el electro pues pa otra y ya esta......y el open air mas grande y abierto y dejaros ya de tanta zapatilla y tanta alpargata a cada uno le gusta la musica qe le sale del cono y listo era lo qe faltaba $\mathrm{xd}$ !

9 de agosto a las 11:09

Marta Liébana Auqué Joder, escribes con el puto culo tronca, asi no se te puede tomar en serio!

9 de agosto a las 11:13

Marta Liébana Auqué Lee un libro y dejate de tanto schranz

9 de agosto a las 11:13

(33) David Dura Nunca entendere Julieta Venegas en el Fib...

14 de julio a las 22.47

Daniela Gonzalez Dedicate por entender tu existencia David y no molestes! :)

14 de julio a las 22.48

(34) Jorge Cano Canito loquillo dice este....jajajajajaja, me descojono!!!

06 de abril a las 19:21

Mario Cremades jorge que pasa con loquillo, le da mil vueltas a todos estos y mira que me gustan, poca cultura debes tener si te ries de loquillo

06 de abril a las 19:25

Alvaro Rigal Rioperez Loquillo el año pasado fue la ostia, poca broma. Y el cartel está muy bien, yo no sé qué gente se hace fan del festival para luego decir que los grupos no le molan.

06 de abril a las 20:04 [...]

Jorge Cano Canito por que no me guste loquillo... poca cultura musical?? anda que....

06 de abril a las 21:51

Jorge Cano Canito Alvaro Rigal, mira majete, me hago fan de los que me sale de los cojones y si no me molan pues no me molan y punto!!! pasa algo??

07 de abril a las 15:40

La interacción en el muro de FB es una práctica discursiva, pero también es en sí misma una práctica social inserta en una red de relaciones de prácticas económicas y culturales en sentido amplio, es un medio de relaciones sociales que deja espacio a diferentes voces que forman de manera dialéctica creencias, valores y deseos, constituyéndose como una forma de comunicación que transforma radicalmente relaciones e identidades. En la práctica social de la interacción discursiva de FB se construye un proceso activo, interpretativo y colaborador de representación del mundo a la vez que una negociación de relaciones sociales e identitaria (Chouliaraki / Fairclough, 1999: 46; Dann / Liebman Parrinello 2007). La plantilla y el medio FB, al proporcionar herramientas para la autopresentación y la construcción del contexto, son un marco comunicativo que orienta las expectativas convencionalizadas y rutinarias situando la interacción festival/público en un marco amistoso en el que se "habla":

People do not "write" to their friends on the Internet they "talk". By and large people engaged in computer- mediated communication tend to conceptualize their communicative acts as conversation despite the fact that they employ written rather than verbal modes. Because the response delay has been so drastically reduced it is much easier to think of communicative acts in terms of a less formal "conversational" mode rather than "writing" which has traditionally been a more formal and structured mode (Giese, 1998).

En la aplicación comercial de FB la identidad de los sujetos está formada heterogéneamente por efecto de los distintos posicionamientos del usuario (Chouliaraki / Fairclough, 1999: 25), que es, a la vez, amigo y cliente: así comprobamos una especial calidad de articulación de las voces sustentada en la hibridación del discurso de la promoción e información turística con la interacción que se desarrolla en una relación vivencial virtual de proximidad.

\section{Conclusiones}

Del análisis de las páginas FB de festivales se desprende cómo el discurso turístico se recontextualiza en el marco de las redes sociales adaptándose a la especificidad del medio y proyectándose hacia una categoría de destinatarios, a la que da voz y a la que se dirige, anticipando, en parte, su re-interpretación y recontextualización (Linell, 1998: 153); el discurso 'amistoso' de FB se apropia del discurso promocional del turismo, "conversacionalizándolo" (Fairclough, 1995) y creando una nueva forma de discurso caracterizada por su hibridez y su polifonía.

La identificación de los núcleos temáticos en el corpus de referencia nos permite afirmar que los participantes en los festivales otorgan gran importancia al cartel y a los acontecimientos culturales que componen el evento. Asimismo, hemos podido comprobar que una de las motivaciones más significativas del uso de sitios web de redes sociales para un festival es la fidelización de los clientes, que es fundamental para el éxito de la organización de eventos artísticos y culturales (Grappi / Montanari, 2011). Las razones más significativas por las que asistir y volver a un festival pueden sintetizarse en las emociones vividas, el hedonismo- un beneficio que coincide con el placer y la alegría, que son elementos fundamentales en un evento intangible, experiencial y recargado emocionalmente -y la identificación social, entendida como el grado en el que un consumidor percibe un sentimento de conexión con otros consumidores, y el significado emocional de esta percepción en el contexto de un festival (Grappi / Montanari, 2011: 1129-1130). La presencia en FB de los festivales permite amplificar y cimentar la experiencia social de los individuos, otorgándoles una recompensa hedonística y emocional que, a su vez, les inclinará a afiliarse con otros participantes aumentando, de esta forma, su nivel de identificación social y reforzando su identidad (Grappi / Montanari, 2011: 1131, 1138). El uso de redes sociales en un ámbito turístico rellena, pues, un hueco en la comunicación promocional ya que no solo facilita la in- 
teracción con la comunidad de referencia y la obtención de datos sobre la satisfacción del cliente, sino que ejerce una influencia positiva en las intenciones de comportamiento de los turistas.

\section{Bibliografía}

Androutsopoulos, Jannis

2006 "Introduction: Sociolinguistics and computer-mediated communication”. Journal of Sociolinguistics, 10/4: 419-438.

Benhamou, Françoise

2004 L'economia della cultura. Bologna: Il Mulino.

boyd, D. M. / Ellison, N. B.

2007 "Social network sites: Definition, history, and scholarship", Journal of Computer-Mediated Communication, 13(1), article $11 \mathrm{http://jcmc.indiana.edu/vol13/}$ issue1/boyd.ellison.html (31.10.2011).

Calle Vaquero, Manuel de la

2002 La ciudad histórica como destino turistico. Barcelona: Ariel.

Calvi, Maria Vittoria

2006 Lengua y comunicación en el español del turismo. Madrid: Arco Libros.

Calvi, Maria Vittoria

2010 "Los géneros discursivos en la lengua del turismo: una propuesta de clasificación”. Ibérica, 19: 9-32.

Calvi, Maria Vittoria

2011 "Pautas de análisis para los géneros del turismo". En Calvi, Maria Vittoria / Mapelli, Giovanna (Eds.), La lengua del turismo. Géneros discursivos y terminología (pp. 19-45). Bern: Peter Lang.

Fairclough, Norman

1995 Media Discourse. London: Edward Arnold.

Chouliaraki, Lilie / Fairclough, Norman

1999 Discourse in Late Modernity. Rethinking Critical Discourse Analysis. Edimburgh: Edimburgh University Press.

Dann, Graham M. S. / Liebman Parrinello, Giuli

2007 "From Travelogue to Travelblog: (Re)-negotiating Tourist Identity". Acta Turistica 19/1: 7-29.

Frey, Bruno S.

2003 "Festivals". En Towse, Ruth (Ed.), A Handbook of Cultural Economics (pp. 232-236). Cheltenham, UK, and Northampton, Usa: Edward Elgar http://www. bsfrey.ch/articles/D_173_03.pdf (31.10.2011)

Garibaldi, Roberta

2011 "Un quadro di riferimento". En Garibaldi, Roberta y Peretta, Roberto (Eds.), Facebook in tourism. Destinazioni turistiche e Social Network (pp. 15-32). Milano: FrancoAngeli.

Giese, Mark

1998 "Self Without Body; Textual Self-Representation in an Electronic Community". First Monday: A Peer Reviewed Journal on the Internet, 3, 4, 6 April 1998, http://firstmonday.org/htbin/cgiwrap/bin/ojs/index. php/fm/article/view/587/508 (31.10.2011).
Giddens, Anthony

1994 [1990] Le conseguenze della modernità. Bologna: Il Mulino.

Grappi, Silvia / Montanari, Fabrizio

2011 "The role of social identification and hedonism in affecting tourist re-patronizing behaviours: The case of an Italian festival". Tourism Management, 32: 11281140 .

Hernández Toribio, Isabel / Vigara Tauste, Ana María

2007 "El lenguaje coloquial juvenil en la publicidad de radio y televisión". Revista de Estudios de Juventud, 78: 141-160, http://www.injuve.es/contenidos.downloadatt.action?id=912664829 (31.10.2011).

Herring, Susan C.

2004 "Computer-Mediated Discourse Analysis: An Approach to Researching Online Behavior". En Barab, S.A., Kling, R. / Gray, J.H. (Eds.). Designing for Virtual Communities in the Service of Learning (pp. 338-376). New York: Cambridge University Press.

Linell, Per

1998 "Discourse across boundaries: On recontextualizations and the blending of voices in professional discourse". Text, 18 (2): 143-157.

López Palacios, Íñigo

2011 "Turismo de playa y festival”, El País, 25/07/2011, http://www.elpais.com/articulo/revista/agosto/Turismo/playa/festival/elpten/20110725elpepirdv_1/Tes (31.10.2011).

Reyes, Graciela

1994 Procedimientos de cita: citas encubiertas y ecos. Madrid: Arco Libros.

Yus, Francisco

2001 Ciberpragmática: el uso del lenguaje en Internet. Barcelona: Ariel.

\section{Notas}

1 "Había que cambiar. La ciudad se había asociado durante años al Inserso. Necesitábamos a los jóvenes" sintetiza el alcalde de Benidorm en el artículo de El País.

2 Este concepto es fluido e indeterminado; en la literatura sobre el tema (Herring, 2004, Androutsopoulos, 2006) se identifican seis maneras concretas de desglosar los componentes que caracterizan, con varia presencia y repartición, una comunidad virtual:

- Active, self-sustaining participation around a core of regular participants

- Emergence of roles, rituals, and hierarchies

- Evidence of shared history, culture, norms and values

- Self-awareness of the group as an entity that is distinct from other groups

- Solidarity and support as evidenced in, for instance, humor, positive politeness, and reciprocity

- Criticism, conflict, and the emergence of means of confict resolution

3 En todos los posts reproducimos la acentuación y la grafía ori- 
ginales, manteniendo eventuales errores.

4 Las comunicaciones oficiales del FIB, que tiene un amplio público anglosajón, van en español e inglés.

Recibido:

$27 / 12 / 2011$

Reenviado:

$16 / 2 / 2012$

Aceptado:

$5 / 3 / 2012$

Sometido a evaluación por pares anónimos 